\title{
Methanol intoxication presented with acute coronary syndrome
}

\author{
Büşra Güvendi Şengör*, Berhan Keskin, Ahmet Güner and Murat Gücün \\ Kartal Kosuyolu Research and Education Hospital: Denizer caddesi Cevizli Kavşağı, Kartal, İstanbul,Turkey
}

\begin{abstract}
Methanol intoxication often leads to acute mortality and morbidities such as blindness, neurologic sequelae. Metabolic acidosis is responsible for most systemic adverse effects of intoxication. Although clinical course has been well known, there is a little data about cardiac presentation in the literature. In this case report, we present a 66-year-old man with a subacute inferior myocardial infarction associated with methanol intoxication.
\end{abstract}

\section{Introduction}

Methyl alcohol (methanol) is a colourless, volatile liquid which is used in industry, agriculture and sometimes used for alcholic beverages. Even if the methanol has a low toxicity, its metabolites such as formaldehyde and formic acid are extremely toxic. Accidental or intentional exposure to methanol causes a life-threating systemic intoxication. While intoxication often has been associated with ingestion, it can also occur with inhalation or skin absorption. Methanol metabolizes in the liver rapidly and its metabolites cause a metabolic acidosis with an elevated anion gap. Ocular, gastrointestinal, neurological symptoms are common. If the diagnosis of methanol intoxication is not made and its treatment is not initiated promptly, it can result in death [1-2].

\section{Case report}

A 66-year-old man presented to the emergency department with chest pain, dyspnea and confusion. The patient developed respiratory arrest shortly after presentation. The trachea was intubated and mechanical ventilation was initiated. CT and MRI showed no cerebrovascular disorder. The ECG revealed pathological Q wave, ST segment elevation in leads II, III and aVF with increased troponin level (troponin level: $21.350 \mathrm{ng} / \mathrm{ml}$, reference value $<0.04 \mathrm{ng} / \mathrm{ml}$ ) (Figure 1). The patient underwent coronary angiography for subacute inferior myocardial infarction. The coronary angiography revealed $90 \%$ occlusion of the obtuse marginal (OM) branch of the circumflex artery, critical stenosis $(70 \%)$ of the left anterior descending artery (LAD) and diagonal branch of LAD, $40 \%$ occlusion of the right coronary artery with thrombolysis in myocardial infarction (TIMI) grade 3 flow (Figures 2A-2C). Emergency percutaneous coronary intervention (PCI) was not performed because of thinned OM (diamater $<2 \mathrm{~mm}$ ) and TIMI grade 3 flow. Medical treatment was decided and elective LAD PCI was scheduled. After the cardiac catheterization, the patient was transferred to the coronary intensive care unit. The echocardiography revealed 55\% ejection fraction with inferior hypokinesia, mild mitral regurgitation and moderate tricuspid regurgitation. An arterial gas analysis revealed metabolic acidosis $(\mathrm{pH}=7.05, \mathrm{PaCO} 2=24 \mathrm{mmHg}, \mathrm{Na}=142 \mathrm{mmol} / \mathrm{L}$, $\mathrm{K}=6 \mathrm{mmol} / \mathrm{L}, \mathrm{Cl}=110 \mathrm{mmol} / \mathrm{L}$, Bicarbonate $=8.4 \mathrm{mmol} / \mathrm{L})$. Despite the sodium bicarbonate treatment, metabolic acidosis persisted, the patient had no urine output and did not wake up. The patient's clinical course was consulted with a nephrologist. An elevated anion gap $(25-30 \mathrm{mmol} / \mathrm{L})$ suggested intoxication and hemodialysis was scheduled. Patient's relatives reported that he had consumed homemade alcoholic drinks and soon he had suffered from visual blurring before getting confused. Methanol intoxication was considered strongly and a blood sample was taken to analyze methanol level. Cardiac arrest occurred during hemodialysis. After approximately 20 minutes of cardiopulmonary resusitation, the inotropic therapy was initiated. Ethanol was administered intravenously and ultrafiltration was performed. A methanol level of $30 \mathrm{mg} / \mathrm{dl}$ was detected. When severely persistent hypotension developed, ultrafiltration was discontinued and high dose inotropic theraphy was administered. Despite the treatments, he died on hospital day 2.

\section{Discussion}

Methanol poisoning rarely occurs but if the condition is left untreated, it can be highly lethal. The mortality rates were reported $10 \%$ to $50 \%$ in previous studies [3-4]. Patients' history must be taken into account as a first step of diagnosis. It is of great benefit to know vocational or enviromental exposure and alcohol consuming habits of patients. Learning that the patient had consumed home-made alcoholic drinks before the symptoms appeared, we strongly suspected methanol poisoning. Although metabolic acidosis with an elevated anion gap along with ocular, gastrointestinal and neurological symptoms are suggestive of the diagnosis of methanol intoxication, these are often not specific to methanol poisoning. It is of value to measure plasma methanol level to confirm the diagnosis. Methanol concentrations above $20 \mathrm{mg} / \mathrm{dl}$ are toxic, its values higher than $50 \mathrm{mg} / \mathrm{dl}$ indicate severe poisoning. The severity of metabolic acidosis is a significant factor for

*Correspondence to: Büşra Güvendi Şengör, MD, Kartal Kosuyolu Research and Education Hospital: Denizer caddesi Cevizli Kavşağı No: 2 Postal code:34840 Kartal, İstanbul, Turkey, E-mail: guvendi2861@hotmail.com

Key words: methanol intoxication, subacute inferior myocardial infarction, metabolic acidosis

Received: March 18, 2021; Accepted: April 05, 2021; Published: April 08, 2021 


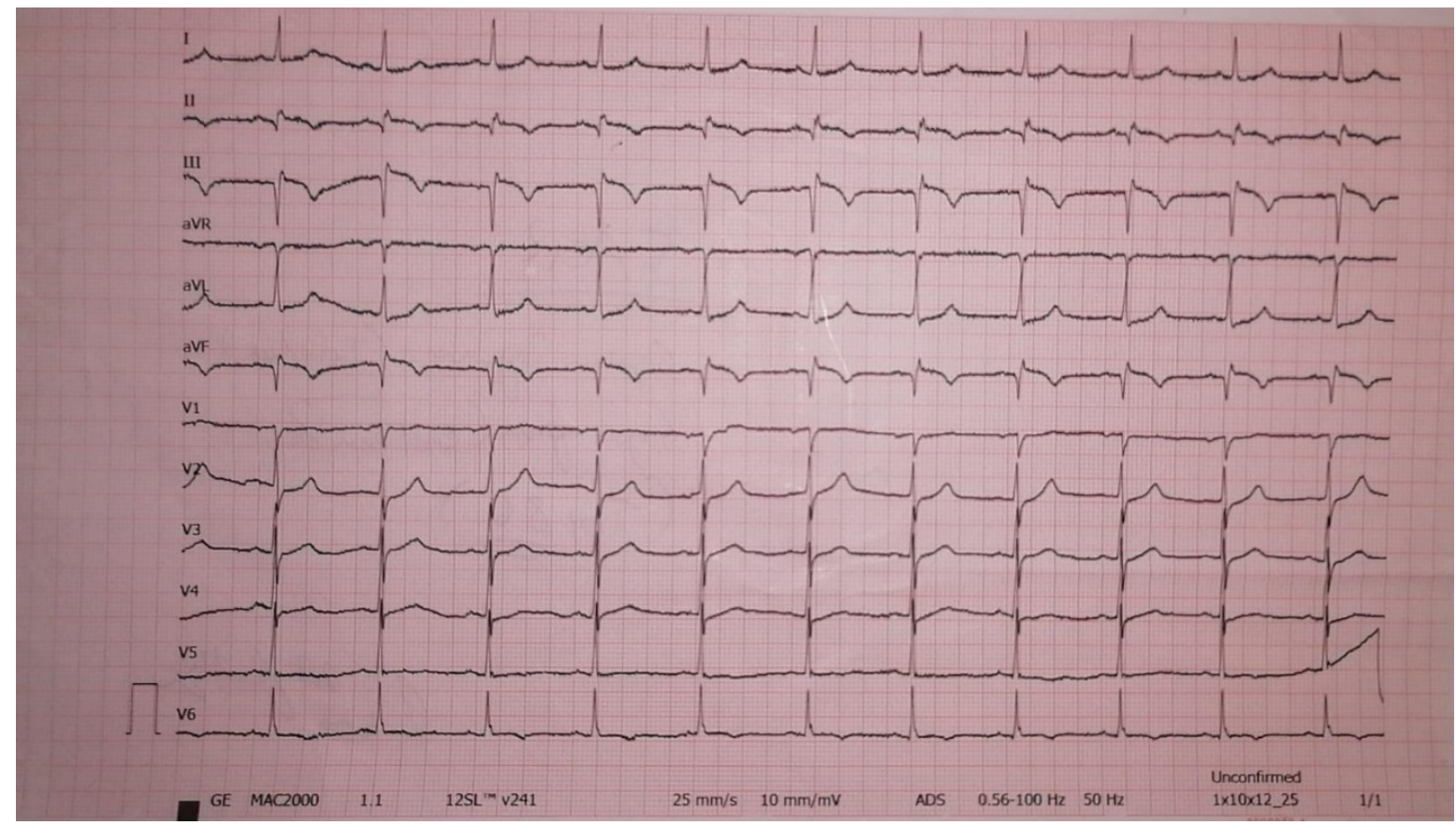

Figure 1. Electrocardiography revealed pathological Q wave, ST segment elevation in leads II, III and aVF
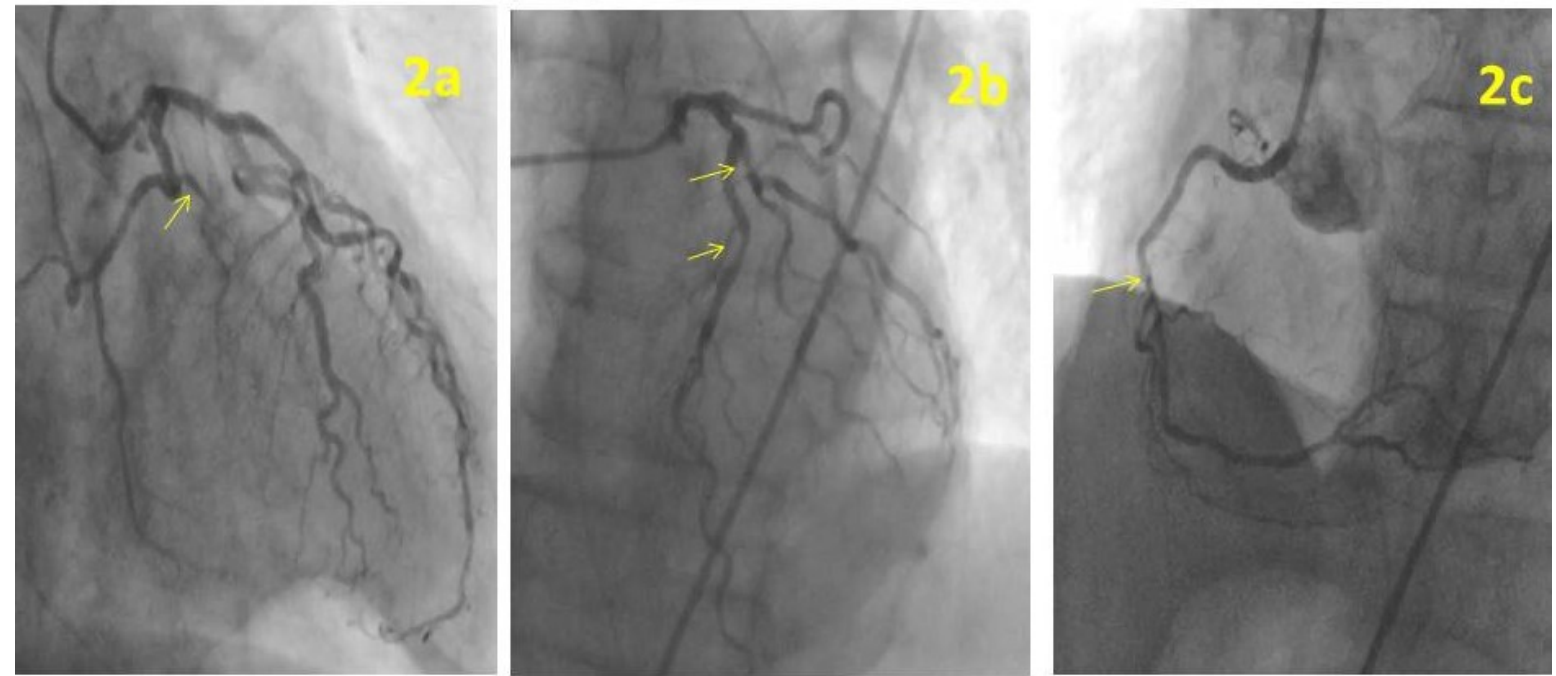

Figure 2A. The coronary angiography revealed $90 \%$ occlusion of the obtuse marginal (OM) branch of the circumflex artery; $\mathbf{2 B}$. $70 \%$ stenosis of the left anterior descending artery (LAD) and diagonal branch of LAD was seen; $2 \mathrm{C}$. The coronary angiography revealed $40 \%$ occlusion of the right coronary artery

prognosis and treatment. Antidotal therapy (ethanol or fomepizol) and hemodialysis should be initiated in eligible patients as soon as possible [2].

Methanol intoxication has been known for a long time but the studies regarding the cardiovascular effects of metnanol toxicity are limited. Some ECG abnormalities were reported like sinus tachycardia, $\mathrm{T}$ wave changes, the increased PR and QTc intervals. The severity of acidosis was considered to be associated with these manifestations [5]. A few cases were also reported about methanol poisoning which presented with reversible severe cardiac failure and rarely acute coronary syndrome [6,7]. A recent study from Iran, which included 356 patients, gave some important and new information about cardiac involvement in patients with methanol poisoning. The study reported that J point elevation, presence of $U$ wave, QTc prolongation and fragmented QRS were the most common ECG findings. It has been the first study to report a prevalence rate of myocardial infarction of 5.3\% [8]. Our patient also presented with a subacute inferior myocardial infarction. Because of its diamater $<2 \mathrm{~mm}$ and a TIMI 3 flow, the PCI was not performed for the culprit lesion in the OM artery. Treatments with antiplatelet and antiischemic medications were administered. The patient died from severe persisted metabolic acidosis caused by methanol poisoning.

\section{Conclusion}

Diagnosis and treatment of methanol poisoning can be challenging, and it is often associated with high mortality. It is essential to diagnose early and to administer timely and effective therapy for survival. Although cardiac presentation is not as common as ocular, gastrointestinal and neurologic manifestations, it should be kept in mind whenever methanol intoxication is suspected. 


\section{Informed consent}

Written informed consent was obtained from the patient's relatives.

\section{References}

1. Kadam DB, Salvi S, Chandanwale A (2018) Methanol Poisoning. J Assoc Physicians India 66(4):47-50

2. Barceloux DG, Bond GR, Krenzelok EP, Cooper H, Vale JA; American Academy of Clinical Toxicology Ad Hoc Committee on the Treatment Guidelines for Methanol Poisoning (2002) American Academy of Clinical Toxicology practice guidelines on the treatment of methanol poisoning. J Toxicol Clin Toxicol 40(4):415-446.

3. Hovda KE, Hunderi OH, Tafjord AB, Dunlop O, Rudberg N, Jacobsen D (2005) Methanol outbreak in Norway 2002-2004: epidemiology, clinical features and prognostic signs. J Intern Med 258(2):181-190.
4. Zakharov S, Pelclova D, Urban P (2014) Czech mass methanol outbreak 2012 epidemiology, challenges and clinical features. Clin Toxicol (Phila) 52(10):1013-1024.

5. Jaff Z, McIntyre WF, Yazdan-Ashoori P, Baranchuk A (2014) Impact of methanol intoxication on the human electrocardiogram. Cardiol J 21(2):170-175. [Crossref]

6. Cavalli A, Volpi A, Maggioni AP, Tusa M, De Pieri G (1987) Severe reversible cardiac failure associated with methanol intoxication. Postgrad Med J 63(744):867-868. [Crossref]

7. Poloková K, Hlinomaz O, Panovsky R (2014) Acute anterior myocardial infarction caused by trombotic occlusion of LAD in patient with acute methanol intoxication. Intervencni a Akutni Kardiologie 13:100-102.

8. Nikoo MH, Arjangzadeh A, Pakfetrat M (2020) Electrocardiographic findings of methanol toxicity: A cross-sectional study on 356 cases in Iran, 20 July 2020, preprint (Version 2) available at Research Square [https://doi.org/10.21203/rs.3.rs-34297/v2].

Copyright: $\odot 2021$ Şengör BG. This is an open-access article distributed under the terms of the Creative Commons Attribution License, which permits unrestricted use, distribution, and reproduction in any medium, provided the original author and source are credited. 